\title{
Capacitação em Atendimento de Urgência e Emergência para o Pré- hospitalar Fixo na Atenção Básica da Coordenadoria Regional de
} \section{Saúde Leste}

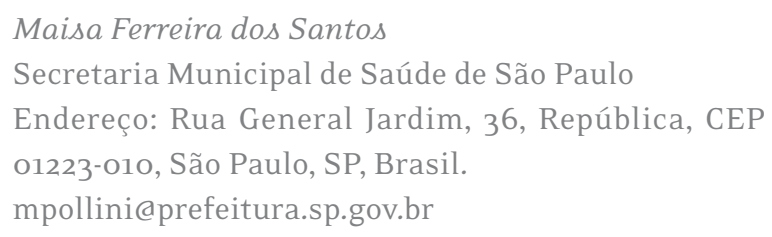

\section{APRESENTAÇÃO}

A Coordenadoria Leste possui, hoje, uma população de 2.483.701 habitantes e 139 Unidades de Saúde, com a seguinte composição: 11o Unidades Básicas de Saúde; 21 Unidades de Assistência Médica Ambulatorial - AMA; cinco Ambulatórios de Especialidade; três Pronto-Atendimentos e 220 Equipes Saúde da Família. 


\section{OBJETIVO}

Relatar o processo de capacitação em atendimento de urgência e emergência para as Unidades que compõem o sistema pré-hospitalar fixo da atenção básica, da Coordenadoria Regional de Saúde Leste.

\section{RESULTADOS}

- De março de 2007 até o momento, foram capacitados 80\% dos funcionários de 14 Unidades, contemplando um total de 671 funcionários;

- As Unidades capacitadas iniciaram uma nova forma de acolher os casos específicos de urgência e emergência, promovendo maior eficácia no atendimento e satisfação dos usuários;

- Mediante o resultado acima descrito, foi necessário iniciar novas capacitações, porém com equipes reduzidas. Em 24 Unidades a capacitação contou com ao menos três profissionais de cada uma delas, sendo: um médico, um enfermeiro e uma auxiliar de enfermagem, que se responsabilizam pela organização do trabalho até a capacitação total da Unidade. 